\title{
ARE COPING STRATEGIES A COP OUT?
}

\section{Susanna Davies}

\section{INTRODUCTION}

Coping strategies are the bundle of poor people's responses to declining food availability and entitlements in abnormal seasons or years. Households do not respond arbitrarily to variability in food supply and, as a result, people living in conditions where their main sources of income (and food) are under recurrent threat develop strategies to minimize risk to immediate food security and to longer-term livelihood security (Frankenberger and Goldstein 1990: 1). This article explores the nature of coping and adaptation in vulnerable livelihood systems, in order to see whether monitoring coping strategies can be useful in predicting food stress.

As coping strategies become an increasingly popular tool in food and livelihood security analysis and policy-making, so has the idea become more befuddled, as researchers and policy-makers confound the two. The central confusion is between coping strategies as fall-back mechanisms during periods when habitual food entitlements are disrupted; and coping strategies as outcomes of fundamental and irreversible changes in local livelihood systems. Clarification is required if coping strategies are to remain a useful conceptual tool, both for monitoring declining food availability and for identifying appropriate interventions. Coping is thus defined as a short-term response to an immediate and inhabitual decline in access to food. Adapting, in contrast, means a permanent change in the mix of ways in which food is acquired, irrespective of the year in question. As Gore (1992: 16) has correctly argued '"coping" essentially means acting to survive within the prevailing rule systems'. When adaptation occurs, such rule systems (or the moral economy) themselves change, as do the livelihood systems in which these rules operate. Indicators which seek to track coping strategies have to be able to differentiate between coping within existing rules and adapting the rules themselves to meet livelihood needs.

Although the importance and proliferation of coping strategies have long been recognised by anthropologists (D'Souza 1985; Campbell 1990), it is only recently that their significance for food security monitoring has been acknowledged. Interest in coping strategies arose particularly in the aftermath of famines in the Sahel and Horn of Africa in the mid 1980 s as a means of understanding why it was that some people survived periods of dearth, whilst others did not. Coping strategies are concerned with livelihood system success rather than failure. This success was explained in part by the re-interpretation of food entitlements, to include a wider range of sources of and calls on entitlements than was habitually associated with food insecure households (Swift 1989). Amongst others, Watts (1983, 1988) and Longhurst (1986) have identified patterns of coping behaviour, based on a widely defined entitlement base, which have been successful in mitigating the threat of famine. In addition, the ability of the rural poor to manage risk and to adapt to longer-term changes in their livelihood systems has been accorded greater importance than in the past (Mortimore 1989). Finally, it has been shown that populations in more marginal environments are probably much better equipped to cope with periods of food stress than those accustomed to more secure conditions (Reardon and Matlon 1989).

The enthusiasm for coping strategies has been further fuelled by redefinitions of household food security in the light of a sustainable livelihood security approach to understanding rural communities. Contrary to conventional wisdom, there is little evidence to show that, apart from conditions of extreme food stress (when livelihood systems have collapsed and death from starvation is imminent), people will always meet food security needs first, irrespective of the consequences of so doing for other aspects of their livelihood security. De Waal (1989) found in the 1984/85 famine in Darfur, Sudan, that people chose to go hungry in order to preserve their assets and future livelihoods. Equally, in comparing the sequential uptake of coping strategies employed in periods of food stress in a number of African and Asian cases, Corbett (1988) found that preservation of assets takes priority over meeting immediate food needs until the point of destitution, when all options have been exhausted. 


\section{HOW USEFUL IS THE CONCEPT OF COPING STRATEGIES?}

Increasingly, coping strategies are regarded as being an inherently good thing, but there is a tendency for them to become shorthand for a complex web of processes at work. This can add to confusion about what coping strategies indicate is happening in famine-prone communities; and what policy options are inferred. Lack of clarity about what 'coping strategies' really are makes for little dynamism in their analysis. Four areas of concern require clarification. First, 'coping strategies' is often used as a catch-all term to describe everything that rural producers do over and above primary productive activities. Whilst it is perhaps justifiable to argue that for food-poor households, all decisions are influenced by and have some bearing on food poverty, it is not analytically helpful to think of everything as a coping strategy. It simply becomes synonymous with the socioeconomy of the household or, more recently, with livelihood security.

Second, focusing on coping strategies in situations of food stress can imply that peopledocope and thus that food insecurity is a transitory phenomenon. This conflicts with the distinction habitually made between transitory and chronic food insecurity (World Bank 1986). If people also 'cope' with chronic food insecurity, then the distinction between their normal behaviour and their coping behaviour is far from clear. At the extreme, all behaviour becomes a coping strategy when, for example, pastoralists have lost their animals and hence their means of primary production. Such groups who have fallen out of the bottom of livelihood systems are uniquely vulnerable and indeed have to cope to survive. But it is conceptually confusing to lump the means of subsistence eked out by such people (the ultra-poor and destitute) with pre-planned strategies used by people within a livelihood system to overcome an exceptionally severe episode of food insecurity. Further, searching for and monitoring coping strategies can mask the collapse of livelihood systems by presupposing that people cope even in subsistence economies which are no longer viable from the point of view of either food or livelihood security. Duffield (1990), drawing on evidence from Sudan, argues that there are parts of the country where the combination of agro-climatic conditions, civil war and impoverishment from repeated famine has rendered some groups incapable of surviving, irrespective of current conditions. These are precisely the circumstances in which famine risks becoming endemic and where rural producers will need to radically alter their livelihood strategies to survive. An emphasis on 'coping' may blind policy-makers and researchers to the need for a radical re-appraisal of the requirements of people's livelihoods in marginal areas.

Third, while coping strategies may be useful in the short-term (and indeed, those who employ them have little option), they may be bad for longer-term development; both from the point of view of those who practice them and of those who seek to intervene to facilitate the development process. Implicit in coping strategies is that the entire working life of subsistence producers is taken up in acquiring food; enabling people to stand still, but preventing them from moving ahead. A focus on coping strategies also hides the (increasing) need of rural producers to develop livelihood strategies which will provide for greater numbers of people in the future. Growth linkages are thus central to the process of adaptation, but rarely included in analyses of coping behaviour. This assertion is, to some extent, contradicted by the sustainable livelihood security approach, insofar as meeting food needs may be pushed into second place behind securing future livelihoods. But this holds only to the point where such choices make those livelihoods more secure in the future than in the present. All too often, future livelihoods are no more secure as a result of these choices, implying that there is no saving in the household; and that livelihoods are dominated by the need to avoid risk, including the risk of investing in production.

Fourth, and linked to this, is the fact that coping strategies are not necessarily economically or environmentally sustainable. De Waal (1989) distinguishes between 'non-erosive' and 'erosive' coping, in order to differentiate those strategies which use extra sources of income and do not erode the subsistence base of the household (thereby compromising future livelihood security), from those which do not entail such costs. There is as yet little evidence to show how the trade-off between subsistence and economic sustainability works in meeting immediate food needs and longer-term livelihood ones. A study of coping strategy use over four years in Mali has shown that the overwhelming characteristic of strategies pursued is that they offer - without exception - uncertain, piecemeal and poorly remunerated means of filling the annual food gap (Davies 1993). To find out more about the subsistence/economic sustainability trade-off, the ability of these strategies 
to reduce vulnerability over much longer periods than a simple cycle of famine and rehabilitation would have to be assessed. On the environmental side, quick correlations between 'abusive' coping strategies (e.g. cutting down trees to sell wood) and environmental degradation are often made. Recent evidence indicates that marginal semi-arid zones are probably much more resilient to degradation than is generally assumed (Behnke et al. 1993). Insofar as coping strategies are concerned, this suggests that much more careful analyses of the environmental consequences of poor people's actions in response to livelihood risk need to be carried out.

These latter two criticisms of coping strategies have implications for the often-advocated (albeit rarely implemented) reinforcement of indigenous coping strategies as a more appropriate and effective method of famine mitigation (and promotion of livelihood sustainability) than distributing emergency food aid once livelihoods have been eroded (e.g. WFP 1989). Reinforcing coping strategies may lock people into a vicious circle of subsistence and coping. If, on the other hand, food insurance for the very poor is provided, it enables them to be economically active (to take risks, to save). Thus, whereas there is an economic efficiency argument for guaranteeing food security, over and above the purely humanitarian one, reinforcing coping strategies may be economically inefficient because it will reinforce the riskaverse survival-orientation of poor people. Indeed, it might be argued that the focus on short-term alleriation and the allied notion of 'coping' create the very conditions of dependency rural producers are often blamed for having.

\section{COPING WITH SECURITY, ADAPTING TO VULNERABILITY}

Coping (in)capacity cannot be separated from the nature and intensity of vulnerability. The reasons why households pursue a particular mix of coping strategies and their timing for so doing depend on a complex range of criteria which are intimately linked to different dimensions of vulnerability, two of the most important of which are resilience and sensitivity (see Bayliss-Smith 1991). ${ }^{1}$ Highly resilient systems have the capacity to bounce back to a normal state after food crises, which is contingent upon having coping strategies which are reserved for periods of unusual stress. The sensitivity of a livelihood system refers to the intensity with which the shock is experienced: in highly sensitive systems, coping strategies are not available to cushion the shock. Further, the greater the sensitivity, the further the system will need to bounce back; consequently, there is a vicious circle between increasing sensitivity, declining resilience and an inability to bounce back.

Coping strategies are the means by which resilient systems weather the bottom of the drought/recovery curve shown in Figure 1 and, if they are to be good indicators of unusual stress, are used only at the point in the curve indicated, and abandoned once recovery is underway. Genuine coping strategies must therefore be distinguished from insurance strategies (undertaken to minimize the risk of production failure) and recovery strategies (designed to facilitate bounce-back).

If, on the other hand, coping strategies are part of a low resilience and highly sensitive livelihood system, they will be used every year in some seasons to bridge the food gap (Figure 2). In this instance, their use can only indicate an anticipated hungry season and not deviations in the norm. If low resilience systems are characterised by fundamental adaptations after each period of severe drought (because they no longer have coping strategies reserved for such periods to facilitate bounce back), then any sequence of coping in subsequent periods of drought will be very different from what went before.

Vulnerable livelihood systems, characterised by properties of low resilience and high sensitivity, thus find it hard to cope. People in secure (resilient and insensitive) livelihood systems practice coping strategies only when necessary, as part of a wider portfolio of risk management. In contrast, people in vulnerable systems are more likely to pursue adaptive strategies, seeking to use all available options at all times to maximize the trade-off between increasing resilience and reducing sensitivity. In so doing, adaptive livelihood systems are moving towards a new equilibrium, part of which is the trade-off between sustainability and subsistence, or seeking to preserve assets for future production, often at the cost of current consumption. The intensity of vulnerability is greatest when proximate and structural

1 Bayliss-Smith draws on Blaikie and Brookfield's (1987) analysis of thesustainability of agricultural ecosystems in distinguishing between these characteristics. 
Figure 1: Coping Strategy Use in Drought/Recovery Cycle in Secure Livelihood Systems

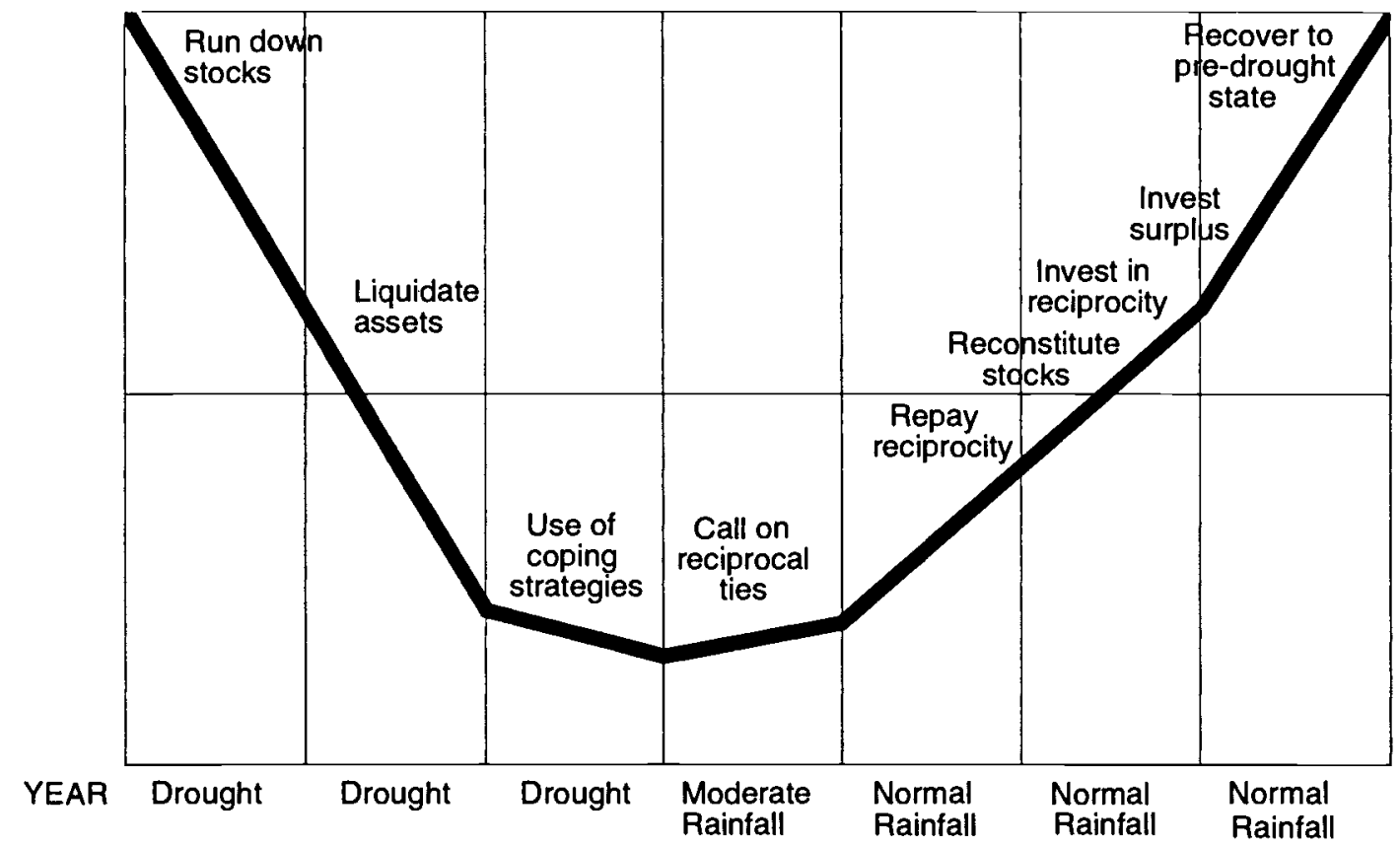

Figure 2: Adaptive Strategy Use in Annual Cycle of Subsistence in Vulnurable Cultivating Livelhood System

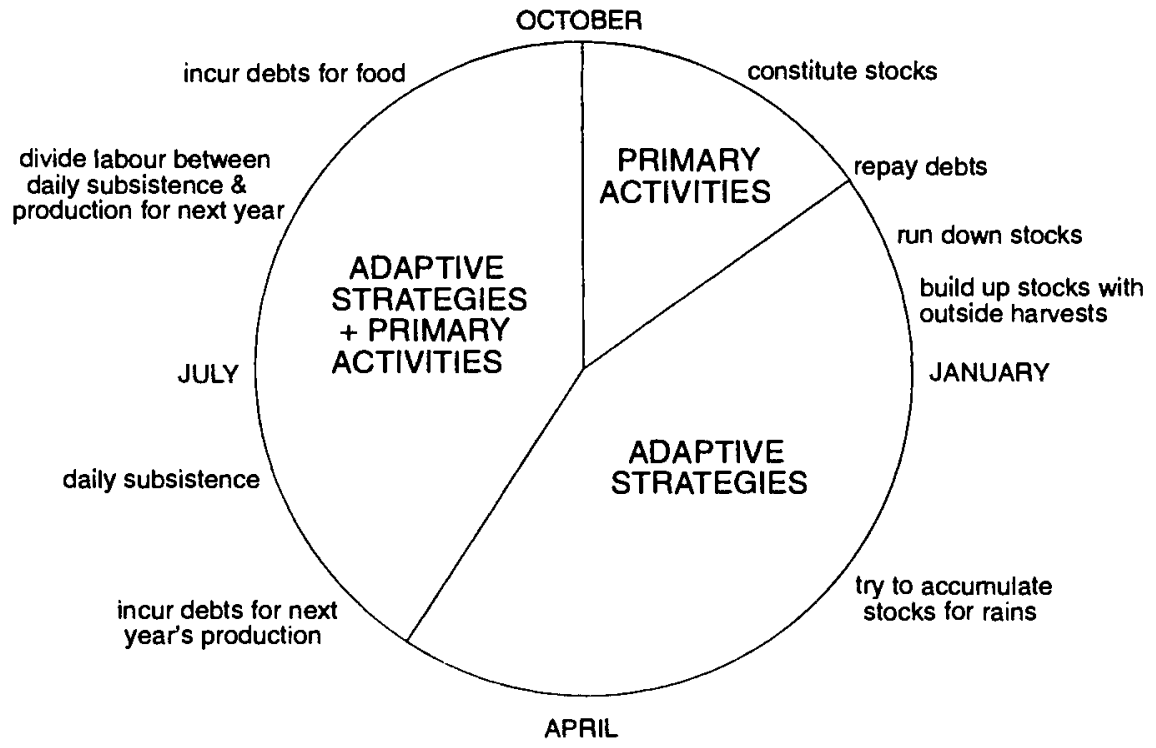


vulnerability coincide. 'Vulnerability is thus a composite of the states of past and current events' (Borton and Shoham 1991), ${ }^{3}$ and structurally vulnerable livelihood systems hit by drought will be less able to cope than secure systems. Within these systems there are, of course, differentially vulnerable households and individuals, further compounding livelihood system vulnerability. Thus Longhurst (1986), for example, notes that in communities with land holding and income inequalities, household responses will differ. Watts (1988) also describes how wealthier households can benefit from the distress sales (of livestock, assets or labour) at depressed prices by poorer members of the community. The most vulnerable people are those who struggle to survive in vulnerable households and vulnerable livelihood systems. It is they who have the most constrained capacity to cope with shocks such as drought; and hence who are most vulnerable to famine. The ability to mitigate this vulnerability is contingent upon their capacity to adapt.

\section{COPING STRATEGIES AND FAMINE EARLY WARNING}

In line with the recognition of coping strategies as a means of explaining how poor households deal with food stress, there has been a call for monitoring their progress within famine early warning systems(EWS), particularly local information systems concerned with early detection of food insecurity, not simply of famine. Finding out what producers do to help themselves to overcome chronic and transitory food shortages - or monitoring their coping strategies - is crucial: to interpret standard indicators of food stress (e.g. does a particular pattern of migration signify a normal or abnormal activity?); to assess the intensity of food insecurity (e.g. if the harvest fails, are there sufficient fall-back options to meet food needs?); and to identify appropriate responses (e.g. do people need food to eat or help in retaining their productive assets?).

There is an appealing symmetry in a coping strategy-based approach to early warning: it can simultaneously predict, and inform how to prevent, famine. Implicit in much (but by no means all) of this call for monitoring coping strategies is a belief that they will not only assist in predicting food crises, but also indicate appropriate and sustainable interventions to mitigate that crisis. Indigenous coping strategies can be reinforced, in preference to imposing external, often late, inappropriate and unsustainable solutions to food crises, epitomized by emergency food aid distributions. Whereas food aid invariably assists producers only once they have lost the means to feed themselves, monitoring coping strategies has the potential to identify ways of protecting and reinforcing system success and adaptation before collapse. If successful, such interventions would warn earlier of the destitution implicit in famine and possibly even prevent it. In so doing, the long-term effects of structural livelihood system vulnerability to food shortages which persist once the crisis is over could be reduced.

Clearly, it is not possible to monitor all the different criteria which determine coping strategy use. Structural factors which determine coping choices are insensitive to short-term changes in the overall food situation, and tracking proximate factors at household level is beyond the scope of even local EWS, let alone those operating over larger areas. Any monitoring system, to be sustainable, has to derive indicators which can be tracked over time and sensibly interpreted without too much difficulty. It is by no means clear that coping strategy indicators of food stress can do this, certainly they cannot by implicitly assuming homogeneity of motive and livelihood status. Even when livelihoods are differentiated, differences between communities and households within the same broad livelihood system can be as great as those between livelihood systems. Further differentiation by individual or household determinants of vulnerability could assist the process; but practically, the spread of combinations of strategy use and of sequences of uptake would be so great as to make monitoring (let alone interpretation) highly complex.

\section{INDICATOR DEVELOPMENT USING COPING STRATEGIES}

The use of coping strategies to develop more appropriate indicators of food stress has been characterized by two - often conflicting - trends. On the one hand, at a conceptual level, outsiders' perceptions of the complexity of vulnerable people's responses to
2 Downing (1990, cited in Frankenberger 1992: 82) similarly distinguishes between baseline and current vulnerability. Future vulnerability refers to the trends associated with long-term food security risks.
3 Cited in Frankenberger (1992: 82). 
drought have improved significantly in the last ten years or so. On the other hand, attempts to operationalize these conceptual advances have been both limited and often unsuccessful. The iteration between conceptual advances and their practical application has often been to the detriment of the latter. Although increasingly advocated, examples of the use of coping strategies to monitor food insecurity are rare. A handful of local level systems in the Sahel and Horn of Africa which incorporate them to some degree have been identified by Buchanan-Smith et al. (1991). Eele (1987), amongst others, has demonstrated how possible sources of information about coping strategies could be grafted on to existing EWS relatively easily. Broadly speaking, there were three phases in the evolution of indicator development based on coping strategies:

1 1970s: during this time coping strategies were ignored by most famine EWS, reflecting the preoccupation with supply of food (but not access to it) and with aggregate indices of supply and demand (epitomized by national food balance sheets).

2 1980s: models of sequential uptake predominated in the 1980 s, especially in the aftermath of the famines in the Sahel and Horn of Africa in the middle of the decade.

3 1990s: a new realism now characterises the potential for indicator-based coping strategies, based on the realisation that earlier models were oversimplified and were often operationally impractical. Whether or not the new realism at a conceptual level can be translated into functioning EWS remains to be seen.

\section{THE 1980S: NICE IDEA, SHAME ABOUT THE PRACTICE}

The ability to monitor coping strategies to predict food crises is predicated upon the assumption that they follow a discernible and repeatable sequence. Evidence from Africa and Asia supports the idea that the range of coping strategies available to rural producers is similar across very different food systems (Longhurst 1986, Downing 1988). Watts (1983), drawing on evidence from northern Nigeria in 1973/ 74 , identified the ten most commonly observed re- sponses to food crisis as follows: collect famine foods; borrow grain from kin; sell labour power (migration); engage in dry season farming (migration); sell small livestock; borrow grain or money from merchants/moneylenders; sell domestic assets; pledge farmland; sell farmland; and migrate out permanently. Corbett (1988), reviewing this and other empirical evidence ${ }^{4}$ for the sequential uptake of coping strategies, identifies the sequence in Table 1 which 'provides a useful tool for analysing the economic behaviour of households prior to and during famines' (ibid.: 1107).

The idea of sequential uptake has been refined to distinguish between insurance strategies and coping strategies. Insurance strategies are those activities undertaken to reduce the likelihood of failure of primary production (e.g. changes in cropping and planting patterns, or in levels and types of investment in primary production such as a shift from cattle to goats by pastoralists). Coping strategies are employed once the principal source of production has failed to meet expected levels, when insurance strategies have failed or are failing, and producers have to literally 'cope' until the next harvest. Thus, Frankenberger and Goldstein (1990) distinguish between various types of risk management and patterns of coping behaviour (e.g. asset depletion, breakdown of community reciprocity, non-farm coping strategies), as well as between types of household assets which will play different roles in the process of coping. On this basis they argue that 'the dilemma facing small-farm households involves ... a trade-off between immediate subsistence and long-term sustainability' (ibid.: 22). Equally, the World Food Programme (WFP 1989) differentiates between accumulation and diversification (or insurance) strategies. The former aim to increase a household's resource base, and the latter to promote a variety of sources of income with different patterns of risk, to avoid the exposure associated with a single income source (ibid.: 3). Accumulation strategies include food stocking, credit schemes, productive investment and investment in education and training. Diversification strategies include agricultural diversification, migration and remittances, and diversification of employment opportunities. A further distinction is made between hungry season strategies used for part of most years and strategies to survive particularly bad years.
4 Corbett considers inter alia Cutler's sequence from Red Sea Province Sudan in 1984 (Cutler 1986); Rahmato's (1987) sequence from Wollo Province, Ethiopia in 1984/85; and de Waal's (1989) sequence from Darfur, Sudan in 1984/85. 
Table 1: The Sequential Use Of Insurance And Coping Strategies

Sequential Use of Examples Of Strategies $\quad$ Characteristics Of Strategies
Strategies

STAGE 1

$\begin{array}{lll}\text { Insurance } & \text { - changes in cropping and planting } & \text { - risk-minimizing } \\ \text { Mechanisms } & \text { practices } & \text { - loss-management } \\ & \text { - sale of smallstock } & \text { - low commitment of domestic } \\ & \text { - reduction of current consumption } & \text { resources } \\ & \text { levels } & \\ & \text { - collection of wild foods } \\ & \text { - use of inter-household transfers and loans } \\ & \text { - increased petty commodity production } \\ & \text { - migration in search of employment } \\ & \text { - sale of possessions (e.g. jewellery) }\end{array}$

\section{STAGE 2}

Disposal of

Productive Assets

(Coping)

- sale of livestock (e.g. oxen)

- sale of agricultural tools sale or

mortgaging of land

- credit from merchants and

moneylenders

- reduction of current consumption

levels
STAGE 3

Destitution distress migration
- high commitment of

domestic resources

Source: Adapted from Corbett 1988 and Frankenberger 1992.

Within the framework of models of sequential uptake, three sets of indicators have been developed to monitor changing coping responses. Building on the work of the World Food Programme, Frankenberger and Hutchinson (1991) summarize these as follows:

1 Early (or leading indicators), that is, changes in conditions and responses prior to the onset of reduced food access. They include: signs of crop failure; lack of pasture (leading to animal deaths, unusual migration patterns, unusual sales of animals); and changes in exchange relationships (e.g. unseasonal price rises of grains, falling casual labour rates);

2 Stress (or concurrent) indicators are those which occur simultaneously with reduced access to food. They include: unusual numbers of migrants in search of work; unusual sales of assets on local markets; unusual sales of land or mortgages; unusually high demand for credit; increased dependence on wild food; reduced food intake (number of meals);

3 Late outcome (or trailing) indicators occur once food access has declined. They include: increased prevalence of undernutrition and morbidity; increased land degradation; land sales; and permanent out migration.

Refinements in the categorization of coping strategies are informed by a desire to simplify complex patterns of decision-making and response. As models of coping strategy use have been refined, so has much justified caution in their application been cast aside. Such warnings include Corbett's (1988: 1109) point that 'variations in observed strategies also suggest that there are few universal indicators of impending famine and famine warning systems 
need to be locally specific'. Further, as Frankenberger (1992: 84) argues, 'models that ignore the locational specificity of ecological and economic aspects are likely to select proxy indicators which are inappropriate or misinterpreted'. Even if at a conceptual level, the necessity to proceed with care is well recognised, in the practical implementation of information systems which incorporate indicators of coping strategy use, there has been a tendency to look for universal truths. If coping strategies are to be employed as predictive indicators of food stress, it is essential that their use by food insecure groups follows discernible patterns capable of being monitored. Otherwise, coping strategies are little more than random responses to food insecurity which can play no role in prediction. It is at this point that the use of coping strategies to monitor changing levels in food security runs into difficulties. Despite the apparent simplicity of models of sequential uptake, operationally they pose a number of difficulties.

The major drawback to such models is that households juggle between different activities simultaneously and in response to the seasonal options available to them. In the case of sales of assets, for example, rural people are highly conversant with the seasonal terms of trade between goods (e.g. livestock and cereals) and will seek to maximize their revenue over a year by playing the market. Although the literature identifies the grey area between strategies as responses to unusual changes in access to food, and strategies as more permanent reactions to fundamentally altered conditions, once coping strategy uptake becomes an indicator of transitory food stress, this grey area must of necessity be ignored. Either use of a particular strategy signals stress or it does not. Attempts to differentiate between why different people pursue a particular strategy at a given moment make for highly complex monitoring requirements.

Second, a coping strategy-based approach to monitoring access to food is criticised, and rejected by most EWS, because its information needs are too complex, expensive and time consuming. In recent years, the thrust of much early warning thinking, and views about information needs for rural development more generally, has been to minimize information requirements or to opt for what advocates of Rapid Rural Appraisal (RRA) term 'optimal ignorance' (McCracken et al. 1988). A coping strategybased approach contradicts this trend, although methodologies can be developed which simplify information collection (see Davies 1993). Further, the raw data used as indicators can be misleading, necessitating the validation of data quality which can further add to the burden of the information system (Frankenberger 1992).

The third obstacle is the capacity to analyse data and to interpret them quickly enough to permit timely response. Almost all concurrent indicators, for example, are prefaced by the word 'unusual', implicit in which is some baseline by which deviations from the norm can be measured. Without such a baseline, indicators are hard to interpret sensibly; and further, what is normal in one context, may be very different from another neighbouring area (Frankenberger 1992). Unusual migration is a frequent casualty in this respect: empty villages after the harvest are used to indicate migration driven by poor harvests, whereas in fact they can be due to habitual reciprocal labour exchanges between neighbouring agro-ecological zones with differing harvest times (part of the moral economy, not of a collapsing food economy). Furthermore, such migration patterns are a function of the usual variability of production in the same agro-ecological zone, or between neighbouring agroecological ones.

Fourth, such models can easily disguise intra-community variation, by failing to account for the fact that one person's coping strategy is another's livelihood. Mortimore (1989), for example, shows how adaptive behaviour to drought over a thirteen year period in Northern Nigeria varies between households, in the same village. Differences in options and choices occur at individual, household, community and livelihood system levels. If a particular activity is identified as being a coping strategy for the purposes of food security monitoring, the assumption is that all people who take up that activity do so in order to cope with food stress. Yet, there is no easy way, for example, of distinguishing between someone who is choosing to go hungry to preserve assets and someone who is hungry and who has no choice, having previously liquidated all assets. Thus, whereas the stress indicator of increased dependence on wild foods appears to be a robust indication of local food entitlements, in fact in many marginal Sahelian communities, there are groups who now habitually depend on wild foods for subsistence in part of every year. If early response is at the heart of monitoring coping strategies, it would be necessary to disaggregate food security profiles for all groups in a given area in a normal year. 
Finally, the models fail to account for changes over time. Coping strategies are not cast in stone and with each cycle of drought and partial rehabilitation, the range of options will change and the rate of take-up of particular coping strategies will vary. Riely (1991), for example, found that in Kordofan, Sudan, asset redistribution and changes in markets meant that the experience of drought itself changes the scope for coping with the next food crisis. So, even if one cycle has been successfully monitored and understood, there is no guarantee that next time around, the same pattern will repeat itself for the same groups of people, in roughly the same proportions.

\section{THE 1990S: THE REALPOLITIK OF COPING STRATEGIES}

Many of those populations living in the Sahel and Horn of Africa, who have been identified as potential beneficiaries of monitoring systems which are based on coping strategies, subsist in low resilience/ high sensitivity livelihood systems which, in turn, are often found in areas of low resilience and high sensitivity in natural resource terms. The difficulty in using these strategies as the basis for developing indicators of food stress may add grist to the mill of those early-warners who argue that systems should remain minimalist and deal only at a high level of aggregation, because they can never collect sufficient information or make sense of it. This is despite the fact that local people already have and make use of such information, and have their own information systems. Broad indicators of output and estimates of projected consumption, perhaps with some proxy indicators of demand such as market prices must suffice: a return to the fashion of the 1970s. Yet, these systems too have real drawbacks, not least their inability to understand how people feed themselves (rather than how they fail to do so), and what kind of interventions would reinforce this process early on in the cycle of drought and destitution, and before livelihood systems become unsustainable. The challenge is to retain the essence of coping strategy-based monitoring, which can fulfil these functions, whilst recognising that ' 1980 s models' for so doing are either too sweeping in their definition of coping strategies and too simplistic in their assumptions about when and why people use them; or alternatively, that more comprehensive '1990s models' present formidable operational drawbacks.

Conceptually, the problem is where to draw the line between behaviour that is principally driven by food stress (coping); and that which is motivated by the need to fundamentally alter the mix of activities required for subsistence (adapting). The policy options for each are very different. Coping strategies indicate that if livelihood systems are given a little one-off support, they can continue to provide security for those who depend on them. Adaptive strategies imply that livelihood systems are moving towards a new equilibrium (or not), necessitating that external support respond to the much more basic constraints encountered in such processes. This, in turn, is central to the identification and fruitful monitoring of coping strategies as indicators of unusual food stress. In structurally vulnerable livelihood systems, people combine coping and adapting by optimising the trade-off between reducing sensitivity and increasing resilience. The implication of this distinction for evolving livelihood systems in marginal areas is that what were once coping strategies increasingly determine the level of food availability within households, irrespective of the year in question, and have hence become part of a process of adaptation. If strategies are used as part of a process of adaptation, rather than as short-term responses to isolated periods of food stress, there are a number of implications for their use as indicators of food stress and for policy. Above all, the notion of repeatable sequential uptake is untenable for the following reasons:

1 The mere fact of using a particular strategy, or sequence of strategies, can indicate nothing about food stress, because some people use them all the time and others do so for part of every year. It is very hard to know in advance what the sequence of use will be and who will use which strategies, unless some historical perspective is incorporated into monitoring.

2 The timing of use will change depending on how evolved the process of adaptation is for a given household or community. What may signal an alarm at a given point in one year or drought cycle will be not necessarily indicate the same thing the next time around.

3 The reasons for uptake will depend on the mix of adaptive strategies available to particular livelihood systems and households within them. This mix is determined by: the characteristics of the strategy in question; where the household is in the process of adaptation; and other constraints and opportunities offered by the overall livelihood system. It is very difficult to monitor the motivation for coping strategy use. 
4 The effectiveness of particular strategies in mitigating food insecurity is even more difficult to discern predictively, particularly if the reasons for pursuing a given strategy are themselves uncertain. Generally, the effectiveness of coping strategies is explained retrospectively to elucidate why famines did not occur, or why some people survived.

Whereas it is possible to monitor strategies, it is not clear what they tell you, unless a distinction is made between coping and adaptive behaviour. Coping strategies are most useful as contextual information which informs about how people are making tradeoffs; and not as clear indicators of something going wrong. Multiple indicators are essential to help minimize drawbacks identified above (Frankenberger 1992). In addition, if coping strategies are to be useful indicators of food stress, it is the intensity of their use (how dependent households are on such strategies in a given season year, compared to 'normal'); their sustainability when this intensity increases (in both an economic and an environmental sense); the motivation for their use (coping or adapting); and their effectiveness in meeting food and livelihood needs (or their costs and benefits), which must be assessed. This will define the threshold between fundamental and longterm changes in livelihoods, and the ability of people to bounce back to how they lived before. How then can indicators be developed to encapsulate the complexity of vulnerable livelihood systems without being unduly complex and infeasible? The first step is to grade coping or adaptive strategies according to local conditions and at livelihood system level, on the basis of these four criteria:

1 Motivation/intensity: a high score for intensity would indicate that the strategy is already pursued by many people and is thus perceived by them to be the best option available. Scoring motivation hinges on whether the strategy is abandoned once recovery is underway. The difference between motivation for and intensity of use could only be made once strategies had been monitored over a number of years. In systems undergoing a process of adaptation, motivation and intensity are part of the process of moving towards a new equilibrium. In systems which are coping, they are to facilitate bounce-back.

2 Effectiveness: a high score would mean that returns to pursuing a particular strategy were more likely than others to assist in filling the food gap, with the least cost to future livelihood security, thereby maximizing the trade-off between reducing sensitivity and increasing resilience.

3 Economic and/or environmental sustainability: high economic sustainability would mean that these strategies could be pursued over time; and high environmental sustainability, that they did not have deleterious effects on the natural resource base. As indicated above, whether or not strategies are environmentally sustainable is a much more complex issue than much of the desertification of semi-arid lands literature suggests. Certainly, it should not be assumed that apparently 'abusive' strategies always have deleterious and irreversible consequences for the environment.

In a study of coping options in Mali, it was found not surprisingly - that very few strategies score highly in all, or most, respects, as Table 2 shows (Davies 1993). It is, however, possible to infer which strategies are likely to promote immediate food security without decimating future livelihood security, and which have the potential for reinforcement.

Unpacking strategies in this way is a first step towards meeting the requirements for monitoring adaptation, by identifying the kinds of factors which will influence the intensity of, motivation for and effectiveness of coping/adaptive strategies, as well as their economic and environmental sustainability. Ideally, strategies would be assessed at household level; but realistically, only system level assessment is likely to be feasible for a local monitoring system, although household level constraints must be borne in mind, especially when considering who will benefit from the reinforcement of a given strategy. It must be stressed that the overall assessment of coping/adaptive strategies would need to be updated regularly, to reflect the changing opportunities afforded by different strategies over time.

The next step is to derive indicators from Table 2 , as shown in Table 3. Conventionally, the mere fact of pursuing a particular strategy is taken to indicate stress. This may be refined according to the timing of uptake, in both a seasonal sense and in relation to other activities. But the implicit assumption is that it is a coping strategy. Thus, collection of wild foods signals food stress, and especially so if this occurs early in the hungry season. If, on the other hand, a more dynamic multiple-indicator of strategy use 
Table 2: Grading Of Coping/Adaptive Strategies According To Use

\begin{tabular}{|c|c|c|c|c|}
\hline \multirow[t]{2}{*}{ Source Of Strategy } & \multirow[t]{2}{*}{ Example Of Strategy } & \multicolumn{3}{|c|}{ Use Of Strategy } \\
\hline & & $\begin{array}{l}\text { Motivation/ } \\
\text { Intensity }\end{array}$ & Effectiveness & Sustainability \\
\hline Production-based & Artisan Work & Medium & Medium/Low & Econ. Low \\
\hline $\begin{array}{l}\text { CommonProperty } \\
\text { Resource-based }\end{array}$ & $\begin{array}{l}\text { Collection Of } \\
\text { Wild Foods }\end{array}$ & High & Medium/High & $\begin{array}{l}\text { Econ. High / } \\
\text { Env. High }\end{array}$ \\
\hline Reciprocally-based & $\begin{array}{l}\text { Internal Credit } \\
\text { Mechanisms }\end{array}$ & Medium & Medium & Econ. Medium \\
\hline Asset-based & Sale Of Animals & High & Medium & Econ. Low/Medium \\
\hline Labour-based & $\begin{array}{l}\text { Redivision of } \\
\text { Household Labour }\end{array}$ & High & Medium/High & Econ. High \\
\hline Exchange-based & $\begin{array}{l}\text { Very Small Scale } \\
\text { Retailing }\end{array}$ & Medium & Medium/Low & Econ. Medium \\
\hline Migration-based & $\begin{array}{l}\text { Work In Nearby } \\
\text { Livelihood System }\end{array}$ & High/Medium & Medium & $\begin{array}{l}\text { Econ. Medium } \\
\text { Env. Low / Medium }\end{array}$ \\
\hline Consumption-based & Reduce Intake & High & Low/Medium & Econ. Medium/ Low \\
\hline
\end{tabular}

model is employed, it is possible to differentiate between coping and adaptive strategies (motivation); whether or not a strategy is being unusually depended upon by many people (intensity); how effective that strategy is likely to be in filling the food gap and/or preserving assets (effectiveness); and whether it is likely to be effective in the future and capable of (or worth) reinforcing (sustainability). In the case of wild foods, the indicators suggested in Table 3 measure a combination of: changes over time; the seasonality of uptake; production (or availability) levels; current market signals; and predictions of future supply and demand. Taken together, these indicators provide a far clearer picture of the likely meaning of wild food collection, its potential contribution to mitigating food insecurity, and whether or not this strategy should be reinforced, than would a simple recording of the fact that such foods were being collected.

\section{CONCLUSIONS: ARE COPING STRATEGIES A COP OUT?}

Few would dispute the legitimacy of putting indigenous coping strategies firmly on the food security and famine mitigation agenda. Recognition of the central importance of vulnerable people's own responses to the threat of food and livelihood insecurity by planners and policy-makers was long overdue. The reservations raised here about coping strategies - both generally and specifically in the context of their utility as indicators of food stress are not intended to suggest a return to top-down, impositionist approaches, implicit in which is the assumption that vulnerable people are passive victims of insecurity, sitting still when faced with drought until the rains return.

On the contrary: a focus on indigenous capacity to respond is by far the most effective starting point for policies which will combat insecurity in a sustainable manner, by helping to optimise the subsistence/sustainability trade-off. Yet the danger that coping strategies become a cop out is clear: not because they are unimportant; but rather because of the tendency for them to become shorthand for complexities which need to be understood before they can be simplified for policy-making and implementation. If not fully understood, coping strategies justify - and indeed legitimate - short-term response, even though this is of ten inappropriate. In the quest to use coping strategies in policy-making and plan- 
Table 3: Examples Of Indicators To Monitor The Use Of Coping/Adaptive Strategies

\begin{tabular}{|c|c|c|c|c|c|}
\hline \multirow{2}{*}{$\begin{array}{l}\text { Source of } \\
\text { Strategy }\end{array}$} & \multirow{2}{*}{$\begin{array}{l}\text { Example of } \\
\text { Strategy }\end{array}$} & \multicolumn{4}{|c|}{ Indicator Of Strategy Use } \\
\hline & & Motivation & Intensity & Effectiveness & Sustainability \\
\hline $\begin{array}{l}\text { Production- } \\
\text { based }\end{array}$ & Artisan Work & $\begin{array}{l}\text { Carried out every } \\
\text { year or unusually? }\end{array}$ & $\begin{array}{l}\text { Appearance of } \\
\text { goods on market }\end{array}$ & $\begin{array}{l}\text { Terms Of Trade } \\
\text { Goods/Millet }\end{array}$ & Demand For Goods \\
\hline $\begin{array}{l}\text { Common } \\
\text { Property } \\
\text { Resource- } \\
\text { based }\end{array}$ & $\begin{array}{l}\text { Collection of } \\
\text { wild food }\end{array}$ & $\begin{array}{l}\text { Carried out every } \\
\text { year or unusually? }\end{array}$ & $\begin{array}{l}\text { Timing of } \\
\text { collection } \\
\text { Pressure on foods } \\
\text { Availability } \\
\text { on market }\end{array}$ & $\begin{array}{l}\text { No. of weeks } \\
\text { of food supply }\end{array}$ & $\begin{array}{l}\text { Stability of supply } \\
\text { over time }\end{array}$ \\
\hline $\begin{array}{l}\text { Reciprocally- } \\
\text { based }\end{array}$ & $\begin{array}{l}\text { Internal } \\
\text { Credit } \\
\text { Mechanisms }\end{array}$ & $\begin{array}{l}\text { To buy food or } \\
\text { invest in production? }\end{array}$ & $\begin{array}{l}\text { Price and } \\
\text { availability of } \\
\text { credit }\end{array}$ & $\begin{array}{l}\text { Price of credit } \\
\text { (compared to } \\
\text { formal channels) }\end{array}$ & $\begin{array}{l}\text { Availability of } \\
\text { credit }\end{array}$ \\
\hline Asset-based & $\begin{array}{l}\text { Sale Of } \\
\text { Animals }\end{array}$ & $\begin{array}{l}\text { Distress sales or } \\
\text { habitual disposals? }\end{array}$ & Price of livestock & $\begin{array}{l}\text { Terms of trade } \\
\text { livestock/millet }\end{array}$ & $\begin{array}{l}\text { Type of animals } \\
\text { sold (seed of } \\
\text { herd?) }\end{array}$ \\
\hline Labour-based & $\begin{array}{l}\text { Redivision of } \\
\text { household } \\
\text { labour }\end{array}$ & $\begin{array}{l}\text { To subsist or to } \\
\text { protect livelihood? }\end{array}$ & $\begin{array}{l}\text { Who is doing } \\
\text { what compared } \\
\text { to habitual } \\
\text { seasonal activities? }\end{array}$ & $\begin{array}{l}\text { No. of weeks of } \\
\text { food supply from } \\
\text { unusual activities }\end{array}$ & \\
\hline $\begin{array}{l}\text { Exchange- } \\
\text { based }\end{array}$ & $\begin{array}{l}\text { Very small- } \\
\text { scale retailing }\end{array}$ & $\begin{array}{l}\text { To subsist or protect } \\
\text { livelihood? }\end{array}$ & $\begin{array}{l}\text { No. of traders on } \\
\text { markets }\end{array}$ & Margins on trade & $\begin{array}{l}\text { Saturation of } \\
\text { market for small- } \\
\text { scale trade? }\end{array}$ \\
\hline $\begin{array}{l}\text { Migration- } \\
\text { based }\end{array}$ & $\begin{array}{l}\text { Work in } \\
\text { nearby } \\
\text { livelihood } \\
\text { system }\end{array}$ & $\begin{array}{l}\text { Habitual or unusual } \\
\text { migration? }\end{array}$ & $\begin{array}{l}\text { No. of people } \\
\text { looking for work } \\
\text { in productive } \\
\text { zones }\end{array}$ & $\begin{array}{l}\text { Rates and type of } \\
\text { remuneration }\end{array}$ & \\
\hline $\begin{array}{l}\text { Consumption- } \\
\text { based }\end{array}$ & Reduce intake & $\begin{array}{l}\text { To protect assets } \\
\text { of last resort? }\end{array}$ & $\begin{array}{l}\text { Timing of reduction } \\
\text { (relative to hungry s }\end{array}$ & season) & $\begin{array}{l}\text { Health of } \\
\text { population }\end{array}$ \\
\hline
\end{tabular}

ning, hard choices have to be made between operational feasibility and confronting the complexity of - and limitations to - indigenous response, close to where the action is. This includes appropriate responses to long-term changes in people's livelihoods.

People living in marginal environments have always lived with risk and a portfolio of options, and are well aware of the pathways that follow if their efforts to mitigate proximate stress are unsuccessful. They are fairly clear about how their livelihoods have changed over a two to three generation timeframe. To some extent, the conceptual confusion arising from researchers' and policy-makers' failure to grasp the complexities of adaptation is of our own making. It implies that the immense amount of thinking about these issues in the developed world and in capital cities in the south needs to be supported by much more information about how poor people themselves see coping and adaptation and what this entails for policy and practice: greater complexity;greater innovation and risk-taking; more time and money spent closer to where the action is. But this is only worth doing - and the approach to EWS suggested only relevant - if monitoring and reinforcing indigenous coping strategies is part of a wider livelihood monitoring and reinforcing system based on the recognition that people's lives are changing irrevocably. Such a system needs to be designed to detect collapsing livelihoods, with a view to saving livelihoods not only lives. 


\section{REFERENCES}

Bayliss-Smith, T., 1991, 'Food security and agricultural sustainability in the New Guinea Highlands: vulnerable people, vulnerable places', IDS Bulletin, Vol 22 No 3: 5-11

Behnke, R., Schoones I., and Kerven C., (eds), 1993, Range Ecology at Disequilibrium: New Models of Natural Variability and Pastoral Adaptation in African Savannas, London: Overseas Development Institute, London

Blaikie, P. and H. Brookfield, 1987, Land Degradation and Society, London and New York: Methuen

Borton, J. and Shoham, J., 1991, Mapping vulnerability to food insecurity: tentativeguidelines for WFPOffices', mimeo, Study commissioned by the World Food Programme, Relief and Development Institute, London

Buchanan-Smith, M., Davies S. , and Lambert, R., 1991, 'Guide to famine early warning systems in the Sahel and Horn of Africa: a review of the literature. Volume $2^{\prime}$, IDS Research Report, No. 21, Brighton: IDS

Campbell, D.J., 1990, 'Strategies for coping with severe food deficits in rural Africa: review of the literature', Food and Foodways, Vol. 4 No. 2: 143-162

Corbett, J.E.M., 1988, 'Famine and household coping strategies', World Development, Vol 16 No 9: 1009-1112

Cutler, P., 1986, 'The response to drought of Beja famine refugees in Sudan', Disasters, Vol 10 No 3: 181-88

Davies, S., 1993, 'Versatile livelihoods: strategic adaptation to food insecurity in the Malian Sahel', Report to ESCOR Overseas Development Administration, IDS, Brighton

De Waal, A., 1989, Famine that Kills: Darfur, Sudan, 19841985, Oxford: Clarendon Press, Oxford

Downing, T.E., 1988, 'Climatic variability, food security and smallholder agriculturalists in six districts of Central and Eastern Kenya', unpublished PhD Dissertation, Clark University

_- 1990, 'Assessing socio-economic vulnerability to famine: frameworks, concepts and applications', FEWS Working Paper No. 2.1, USAID Famine Early Warning System project, Washington D.C.

D'Souza, F., 1985, 'Anthropology and disasters', Anthropology Today, Vol 1, No 1: 18-19

Duffield, M., 1990, 'Sudan at thecross-roads: fromemergency procedures to social security', IDS Discussion Paper, No 275, Brighton: IDS

Eele, G. 1987، 'Data sources for timely warning in nutritional surveillance', in 'Figures for food in Africa', Proceedings of the Workshopon Statistics in Support of African Food Policies and Strategies, Brussels, 13-16 May, 1986, Eurostat News, Special Edition

Frankenberger, T.R., 1992, Indicators and data collection methods for assessing household food security' , inS. Maxwell and T.R. Frankenberger (eds), Household Food Security:
Concepts, Indicators, Measurements-A Technical Review, New York: UNICEF and Rome: IFAD: 73-134

- and D.M.Goldstein, D.M., 1990,'Food security, coping strategies and environmental degradation', Arid Lands Newsletter, Vol 30, Tucson: Office of Arid Lands Studies, University of Arizona: 21-27

- , and Hutchinson C. F., 1991, 'Sustainable resource management based on a decentralised food security monitoring system', Discussion Paper, mimeo, Tucson: Office of Arid Lands Studies, College of Agriculture, University of Arizona, April

Gore, C., 1992, 'Entitlement relations and 'unruly' social politics: a comment on the work of Amartya Sen', mimeo, Brighton: IDS

Longhurst, R., 1986, 'Household food strategies in response to seasonality and famine', IDS Bulletin, Vol 17 No. 3: 27-35

McCracken, J., Pretty J., and Conway G., 1988, An Introduction to Rapid Rural Appraisal for Agricultural Development, London: IIED

Mortimore, M.J., 1989, Adapting to Drought: Farmers, Famines and Desertification in West Africa, Cambridge: Cambridge University Press

Rahmato, D., 1987, 'Famine and survival strategies: a case study from North East Ethiopia', Food and Famine Monograph Series, No 1, Addis Ababa: Institute of Development Research, Addis Ababa University, May

Reardon, T., and Matlon, P., 1989, 'Seasonal food insecurity and vulnerability in drought-affected regions of Burkina Faso', in D.E. Sahn (ed.), Seasonal Variability in Third World Agriculture: The Consequences for Food Security, Baltimore and London: John Hopkins University Press

Riely, F., 1991, 'Household responses to recurrent Ddrought: a case study of the Kababish pastoralists in Northern Kordofan, Sudan', in Famine and Food Policy Discussion Papers, No 6, Washington D. C.:International Food Policy Research Institute

Swift, J., 1989, 'Why are poor people vulnerable to famine?', IDS Bulletin, Vol 20 No 2: 8-15

Watts, M., 1983, Silent Violence, Food, Famine and Peasantry in Northern Nigeria, Berkeley: University of California Press

1988 , 'Coping with the market: uncertainty and food security among Hausa peasants', in I. De Garine and G.A. Harrison, (eds), Coping with Uncertainty in Food Supply, Oxford: Clarendon Press: 260-290

WFP, 1989, 'Review of food aid policies and programmes: anti-hungerstrategies of poor households and communities: roles of food aid, Report NoWFP/CFA:27/P/INF/1 Add.1, WFP, Rome

World Bank, 1986,Poverty and Hunger: Issues and Options for Food Security in Developing Countries, World Bank Policy Study, Washington D.C. 